\title{
The association between dietary inflammatory index and gastric cancer: A case control study
}

\section{Ahmad Mujtaba Barekzai}

Tehran University of Medical Sciences

Azadeh Aminianfar

Tehran University of Medical Sciences

\section{Seyed Mohammad Mousavi}

Tehran University of Medical Sciences

Ahmad Esmaillzadeh ( $\nabla$ a-esmaillzadeh@tums.ac.ir)

Tehran University of Medical Sciences

\section{Research}

Keywords: Dietary inflammatory index, DII, FFQ, gastric cancer, case-control

Posted Date: May 27th, 2020

DOI: https://doi.org/10.21203/rs.3.rs-30757/v1

License: @ (1) This work is licensed under a Creative Commons Attribution 4.0 International License. Read Full License 


\section{Abstract \\ Background}

No report is available about diet-disease associations in the understudied region of Afghanistan. Although inflammatory potential of diet has been linked with several cancers, information about gastric cancer is scarce. This study aimed to investigate the relationship between dietary inflammatory index (DII) and odds of gastric cancer in Afghanistan.

\section{Methods}

In this hospital-based case-control study, we enrolled 90 newly-diagnosed cases of gastric cancer and 180 age ( \pm 5$)$ and sex-matched controls. All cases were pathologically confirmed gastric cancer patients, with no history of any type of other pathologically confirmed cancers. Controls were healthy individuals and relatives of patients in the hospital. Dietary assessment was done by a pre-tested food frequency questionnaire. DII was calculated based on energy-adjusted amounts of several foods and nutrients with inflammatory or antiinflammatory potential, as introduced by earlier studies.

\section{Results}

Mean age of study participants was 54 years, of them $73 \%$ were males. After adjustment for age and sex, individuals in the highest tertile of DIl were 2.47 times ( $95 \% \mathrm{Cl}$ : 1.31-4.66) more likely to have gastric cancer compared with those in the lowest tertile. Further adjustment for other potential confounders did not substantially affect the association; such that participants with the greatest DII had approximately 3.59 times $(95 \% \mathrm{Cl}: 1.16,11.02)$ increased odds of gastric cancer than those with the lowest adherence. Additional adjustment for BMI strengthened the association (OR: 3.75; 95\% Cl: 1.14-12.30).

\section{Conclusion}

We found a significant positive association between inflammatory potential of diet and risk of gastric cancer. Further studies with prospective nature are required to confirm this association.

\section{Introduction}

Gastric cancer is one of the most common cancers worldwide[1]. In developed countries, gastric cancer is 2.2 times more likely to be diagnosed in males than females[2]. Based on GLOBOCAN data at 2018, gastric cancer is the 5th most common neoplasm and the 3rd most deadly cancer[3,4]. The incidence and mortality rate of gastric cancer is the highest one in Eastern and Central Asia and Latin America [5, 6]. In East Asia, the average incidence is 32.1 per 100,000 among males and 13.2 among females [7]. According to WHO estimates, there are around 19,450 new cancer cases from 36 million populations in Afghanistan in 2018, which is likely to be an underestimation. Gastric cancer is the second most common cancer among Afghan men and the fourth most common cancer among Afghan women in 2018 [8].

Several factors may contribute to the incidence of gastric cancer including genetic [9], helicobacter pylori infection [10], smoking [11], alcohol intake [12], chemical exposure [13], gender [14], race/ethnicity [15, 16], and obesity [17]. Dietary intakes have long been associated with the risk of gastric cancer. For instance, a case-control study from Uruguay showed that consumption of rice, salted meat, stewed meat, white bread, potatoes, and tubers can increase the risk of gastric cancer [18]. On the other hand, some studies showed that the consumption of raw vegetables, fruits, legumes, and black tea were not associated with increased risk of gastric cancer [19, 20]. Recently, Dietary Inflammatory Index (DII) has been developed to assess the inflammatory potential of the diet. DII ranks subjects in terms of their dietary inflammatory potential from maximum anti-inflammatory to maximum pro-inflammatory [21]. In previous studies, DII has extensively been investigated in relation to the risk of chronic conditions such as obesity [22], diabetes [23], metabolic syndrome and cardiovascular diseases $[24,25]$. DII has also been investigated in relation to the risk of different types of cancer. For instance, DII score was linked to the increased risk of colorectal cancer in US[26]. It has also been examined in relation to esophageal squamous cell cancer[27], breast[28], pancreas[29], bladder[30], gynecological (ovarian and endometrial)[31], prostate[32], and kidney cancers[33]. Some studies have investigated DII in relation to gastric cancer. Findings from Korea [34], Iran [35], Uruguay [18], and Italy [36], revealed that greater DII score was associated with increased risk of gastric cancer.

Data on the link between diet and disease are very limited in Afghanistan. Given the particular nature of diet in Afghanistan along with different factors influencing the risk of gastric cancer, it seems that investigating diet-gastric cancer relations in this country might move the 
field forward through providing additional information in this regard. This study examined the association between dietary inflammatory index and risk of gastric cancer among Afghan adults.

\section{Materials And Methods}

Study participants: This hospital-based case-control study was conducted on newly diagnosed patients (maximum one month elapsed since the detection) in Kabul, Afghanistan in 2019. Using the formula suggested for case-control studies[37], and hypothesizing that almost $50 \%$ of Afghan population were consuming inflammatory diet[38], we calculated required sample size. Given that those with inflammatory diet would have 2.5 times greater risk of gastric cancer[34,36], we considered the odds ratio of 2.5 . We assumed the type I error of $5 \%$, study power of $80 \%(\beta=0.20)$ and the ratio of controls to cases as 2 . Therefore, the required sample was calculated to be 81 cases and 162 controls. However, we recruited 90 patients with gastric cancer and 180 controls to account for probable drop-outs. Cases were chosen by using convenience-sampling method from the patients with pathologically confirmed gastric cancer during the prior month that had been referred to Jamhuriat Hospital, Kabul, Afghanistan. Cases were aged between 20 and 75 years. The control participants were aged between 20 and 75 years and were relatives of patients. Cases and controls were matched in terms of age $( \pm 5)$ and sex. The individuals with a history of any type of pathologically confirmed cancers (except gastric cancer) and those with a history of chemotherapy or radiotherapy (due to cancer) were not included in the study. All cases and controls provided written informed consent. To conduct the study, permission was first acquired from authorities to get into the hospital. Then the details of the study were explained to the hospital chairman. Cases and controls, that met the inclusion criteria were asked to voluntarily participate in the study. The study was ethically approved by the TUMS Ethics Committee (code: 1398.460).

\section{Assessment of dietary intakes}

Common dietary intakes of participants during a year before the diagnosis of gastric cancer in cases and during a year before the interview in controls were examined by a pre-tested Willett-format food frequency questionnaire (FFQ). We used a specific FFQ that was designed for the current study. This FFQ was consisted of food items, with standard portion sizes, usually consumed by Afghan people. A trained interviewer administered the FFQ through face to face interviews at the presence of individuals who were involved in the preparation and cooking of foods. All reported consumption frequencies were converted to grams per day by using household measures. Daily intakes of energy and nutrients were calculated for each person by using the US Department of Agriculture food consumption database.

Construction of DII: Dietary data derived from FFQ was used to calculate DII scores for all subjects. We calculated DII score, using the approach developed by Shivappa et al[21], based on 29 food parameters (instead of 45 items that was used by Shivappa et al.). We did not consider some items, suggested by Shivappa et al[21], because some items were not available in our data set. The items we used in DII construction include: energy, carbohydrate, fat, protein, fiber, cholesterol, mono-unsaturated fatty acids (MUFAs), poly unsaturated fatty acids (PUFAs), saturated fat (SFAs), vitamin B12, vitamin B6, folic acid, niacin, riboflavin, thiamin, vitamin $A$, vitamin $D$, vitamin $E$, $\beta$-carotene, vitamin C, zinc, selenium, magnesium, iron, caffeine, pepper, onion, garlic and green/black tea. To do this, first energy-adjusted amounts of all 29 nutrients were calculated using residual method[39], to avoid misclassification. Then, we calculated the z score for 29 food parameters by subtracting the "standard global mean" from the amount consumed by each subject. The obtained value was then divided by the "global standard deviation", reported by Shivappa et al[21]. To reduce skewness, we then converted this value to a centered percentile score. The DII score or each food item was then computed by multiplying this value to the respective food parameter effect score reported by Shivappa et al[21]. The overall DII score for each participant was calculated by summing up all foods' DII scores. A higher DII score indicates a more inflammatory diet and a lower DII score indicates a less inflammatory diet.

\section{Assessment of other variables}

To collect information about covariates, a pretested questionnaire was used, in which data on age, sex, marital status, place of residence, education, job, family history of cancers, smoking status, ethnicity, supplements use, drug usage, $\mathrm{H}$. pylori infection, medicine use, socioeconomic status, drinking tea, history of diabetes, consumption of kebab food, fried foods, outdoor food usage, boiled food usage, oils used, salt intake, fatty foods, intra-meal water drinking, intra-meal drinking of other beverages were collected. Short form of International Physical Activity Questionnaire (IPAQ) was used for measuring physical activity of participants through face-to-face interview. All results of the IPAQ were then expressed as Metabolic Equivalents per week (METs/week). Weight was measured to the nearest $0.1 \mathrm{~kg}$ using a digital scale with minimal clothes and without shoes (Seca, Hamburg, Germany). Height was measured to the nearest $0.1 \mathrm{~cm}$ in a standing position, without wearing shoes, using a tape measure and shoulders touching the wall and looking straight forward. Body mass index (BMI) was calculated as weight $(\mathrm{kg})$ divided by height squared $(\mathrm{m} 2)$. All measurements were completed by a trained dietitian.

\section{Statistical analysis}


Cases and controls were compared in terms of several variables related to general characteristics. To do this, we applied Student's t test and chi-square, where appropriate. Then, tertile cut-off points of DIl score were derived based on control participants. This was done to reduce error due to the possibility of changed dietary intakes in patients with gastric cancer. All study participants were categorized based on these cut-off points. Comparison of general characteristics across tertiles of DII was done using one-way ANOVA for continuous variables and chisquare test, for categorical variables. Age- and gender-adjusted intakes of foods and nutrients across tertiles of DII were computed using General Linear Model and compared using ANCOVA. Binary logistic regression was applied to examine the association between DII and gastric cancer in different models. First, we controlled for age (continuous) and sex (male/femal). Further adjustments were made for physical activity (categorical), and family history of cancer (yes/no), SES (low, middle and high), consumption of barbecued foods (categorical), smoking (categorical), drugs use (yes/no) and H. pylori infection (yes/no).

We also adjusted for BMI in the last model to identify obesity-independent association. In all these analyses, the first tertile of DII was considered as the reference category and odds ratios and $95 \% \mathrm{Cls}$ in other tertiles were calculated. The overall trend of ORs across increasing tertiles of DII was examined by considering tertiles of DII as an ordinal variable. All the statistical analyses were carried out using SPSS (SPSS Inc., version 24). P values were considered significant at $<0.05$.

\section{Results}

Mean age of study participants was $54 y$, of them $73 \%$ were males. General characteristics of study participants, separately by cases and controls, and across tertiles of DII are presented in Table 1. Compared to controls, cases had a lower mean weight and BMI and were more likely to be physically active, live in rural areas, be farmer or worker, smokers who smoked $\geq 10$ cigarettes a day, drug users, medicine users, drugs usage, have $\mathrm{H}$. pylori infection, family history of cancer, were from low and middle income families and of Hazara and Uzbek ethnicity. They were less likely to use supplements, and have post-graduate education than controls.

Higher DII was associated with rural residence. There were no significant differences in mean BMI, age, weight and physical activity across categories of DII. No other significant differences were seen in other variables across categories of DII.

Dietary habits of study participants, separately by cases and controls, and across tertiles of DII are presented in Table 2. Compared to controls, cases were more likely to drink hot tea, use kebab, fried foods and outdoor foods, low fat food, high fat food, consume solids oils, have high and very high salt intake, intra-meal water drinking and intra-meal drinking of other beverages. They were less likely to use microwave, median salt intake, consume liquid oil, low salt intake, moderate fat food and use boiled foods than controls. Comparing across tertiles of DII, we found that higher DII was associated with frequent boiled food usage and kebab food. There were no other significant differences across categories of DII.

Consumption of food groups among study participants across tertiles of DII as well as by cases and controls are shown in Table 3 . Compared with controls, cases had higher intakes of refined grains, whole-grains, fish and poultry, green/black tea, red and processed meat and pepper. They consumed lower amounts of fruit, vegetables, legumes, nuts and dairy products than controls. Higher DII was associated with lower intakes of whole-grains, vegetables, legumes and nuts, pepper and high intake of fruit.

Comparing nutrient intakes between cases and control, we found that cases had higher intakes of carbohydrates, proteins, thiamin, iron, MUFA, niacin, b-carotene and lower intakes of total fats, cholesterol, SFA, PUFA, selenium, zinc, riboflavin, vitamins B6, A, C, D, E and B12, folate and dietary fiber compared to controls (Table 4). In addition, higher DII was associated with lower intakes of carbohydrates, total fats, SFA, MUFA, PUFA, magnesium, zinc, selenium, thiamine, riboflavin, niacin, b-carotene, vitamins A, C, E, B12 and B6, folate, dietary fiber and higher intakes of vitamin D.

Multivariable-adjusted odds ratios for gastric cancer across tertiles of DIl are presented in Table 5. After adjustment for age, sex, individuals in the highest tertile of DII were 2.47 times (95\% Cl: $1.31-4.66)$ more likely to have gastric cancer compared with those in the lowest tertile. Further adjustment for other potential confounders did not alter the association much; such that participants with the greatest DII had approximately 3.59 times $(95 \% \mathrm{Cl}: 1.16,11.02)$ increased odds of gastric cancer than those with the lowest adherence. Additional adjustment for BMI made the association strengthened $(3.75 ; 1.14-12.30)$.

\section{Discussion}

In the present study, a significant positive association was seen between dietary inflammatory index and odds of gastric cancer in adult population in Afghanistan. These findings support the hypothesis that people who consume a more pro-inflammatory diet might have higher risk for gastric cancer. The association was independent of potential confounders such as age, sex, BMI and other various 
environmental factors. To the best of our knowledge, this is the first study examining the relationship between DII and risk of gastric cancer in Afghanistan.

Gastric cancer is the 5th most common neoplasm and the 3rd most deadly cancer in Eastern-, Central-Asia and Latin America [3, 5, 6]. Diet is an important modifiable risk factor for gastric cancer prevention [40]. Previous studies have linked individual nutrients or food group to the risk of gastric cancer. A high inflammatory potential of a diet was associated with a higher odd of gastric cancer [41]. DII has recently been associated with a variety of cancer risks such as colorectal [42], breast [28, 43, 44], pancreatic [29], bladder [30, 33], and gastric cancer [36]. In the present case-control study, after adjustment for various confounders, we found that people in the top tertile of DII had 3.59 times greater odds of gastric cancer than those in the bottom tertile. Inflammatory potential of a diet has been previously linked to gastric cancer; however, findings were inconsistent. In line with our findings, several studies demonstrated that some foods with higher pro-inflammatory potential such as red and processed meat, salt, salted food and full-fat dairies were linked to a higher risk of gastric cancer. For instance, a case control study in Italy showed that high intake of salt, meat and salty foods was associated with a higher risk of gastric cancer[45]. Another case- control study in Mexico showed that consumption of salty snacks for more than two times per month was associated with an 80 percent increased risk of gastric cancer[46]. A case control study in Ardabil, Iran, showed that high intakes of salt, red meat and dairy products increase the risk of gastric cancer[47]. In addition, foods and nutrients with anti-inflammatory potential including vegetables, fruit, legumes, vitamin $\mathrm{C}$ and fish were linked to a lower risk of gastric cancer. For instance, a case control study in Northern Italy showed that high intake of green vegetables, fresh fruit and whole-grain was associated with decreased risk of gastric cancer[48]. This was also the case for a case-control study in Korea, where high consumption of fresh vegetables and fruits was inversely associated with risk of gastric cancer[49]. In addition to food items, gastric cancer was positively linked to DII in some other studies. A case control study in Italian adults revealed that higher pro-inflammatory diet was associated with 2.35 times increased risk of gastric cancer[36]. Moreover, in Korean population, people in the highest tertile of DII had a $63 \%$ greater risk of gastric cancer compared to those in the lowest[34]. A case control study in Tabriz, Iran showed that consumed more pro-inflammatory diet had 3.5 times greater risk of gastric cancer than those who consumed a more anti-inflammatory diet[35]. A recent systemic review and meta-analysis revealed that a high inflammatory potential of the diet was associated with a $95 \%$ increased risk of gastric cancer[50]. However, some other studies failed to find such an association. For example, in a survey in Belgium, consumption of lean meat was related to the decrease risk of gastric cancer[51]. In conclusion, despite the positive association of DII with gastric cancer in most studies, given the limitations in these studies, it seems that further research is needed to shed light on this issue.

Similar to other cancers, inflammatory process can lead to the development and aggressiveness of gastric cancer[52]. One of the possible mechanisms through which inflammatory potential of the diet might affect gastric cancer is the up-regulation of various cytokines and chemokines and the recruitment of numerous hematopoietic populations to inflamed gastric tissues. In addition, chronic inflammation stimulates the recruitment of progenitor cell populations to the stomach and their subsequent engraftment[53]. Cytokines can stimulate the activation of inflammatory cells like neutrophils and macrophages, which when activated produce inflammatory mediators, including reactive oxygen species. These mediators impart oxidative stress on the cells in the gastric epithelium. Vitamin $\mathrm{C}$, which is an important antiinflammatory component, neutralizes this oxidative stress reaction[54, 55].

Our study had several strengths. This is the first investigation on diet-disease relations from Afghanistan. We enrolled new cases of gastric cancer who had been diagnosed in the only past 1 month. Therefore, the possibility of changing usual dietary intakes in these patients was reduced. In the analysis we adjusted for a wide range of environmental confounders to reach an independent association between DII and odds of gastric cancer. However, our study has some potential limitations. As with any hospital-based case-control study, recall bias and selection bias should be considered. Dietary habits of hospital-based controls may be different from those of the general population. Although FFQ is the most commonly used approach for assessing dietary intakes in epidemiologic studies, it cannot rule out the possibility of misclassification of study participants. However, we used energy-adjusted DII to reduce misclassification of study subjects. In addition, we had not data on some components of DII including eugenol, ginger, n-3 and n-6 fatty acids, saffron, trans fat, turmeric, thyme/oregano, rosemary and flavonoids which may influence our results. However, previous studies have shown that even without these variables the inflammatory potential of the diet can be represented very well.

\section{Conclusion}

In conclusion, we found a significant positive association between inflammatory potential of diet and risk of gastric cancer. Further studies (e.g. cohort studies) with large sample size are required to establish this association.

\section{Declarations}

\section{Ethical Approval and Consent to participate}

Page 5/12 
The protocol of this study was ethically approved by the Regional Bioethics Committee of Tehran University of Medical Sciences (code: 1398.460). All participants provided written informed consent forms.

\section{Consent for publication}

All authors of this manuscript declared their consent for publication

\section{Availability of data and materials}

The dataset used and analyzed during the current study is available from the corresponding author on a reasonable request.

\section{Competing interests}

All authors declared no potential personal or financial conflicts of interest

\section{Funding}

None.

\section{Authors' contributions}

$\mathrm{AMB}$ and $\mathrm{AA}$ contributed in conception, design, search, statistical analyses, data interpretation and manuscript drafting. SMM and $\mathrm{AA}$ contributed in data clearing, statistical analyses and drafting the manuscript. AE supervised the study. All authors approved the final manuscript for submission.

\section{Acknowledgements}

This research was supported by the School of Nutritional Sciences and Dietetics, Tehran University of Medical Sciences, Tehran, Iran.

\section{Authors' information}

${ }^{1}$ Department of Community Nutrition, School of Nutritional Sciences and Dietetics, Tehran University of Medical Sciences, Tehran, Iran. ${ }^{2}$ Obesity and Eating Habits Research Center, Endocrinology and Metabolism Molecular -Cellular Sciences Institute, Tehran University of Medical Sciences, Tehran, Iran. ${ }^{3}$ Food Security Research Center, Department of Community Nutrition, School of Nutrition and Food Science, Isfahan University of Medical Sciences, Isfahan, Iran

\section{References}

1. Brenner H, Rothenbacher D, Arndt V: Epidemiology of stomach cancer. In Cancer epidemiology. Springer; $2009: 467-477$.

2. Rawla P, Barsouk A. Epidemiology of gastric cancer: global trends, risk factors and prevention. Przeglad gastroenterologiczny. 2019;14:26.

3. Bray F, Ferlay J, Soerjomataram I, Siegel RL, Torre LA, Jemal A. Global cancer statistics 2018: GLOBOCAN estimates of incidence and mortality worldwide for 36 cancers in 185 countries. CA Cancer J Clin. 2018;68:394-424.

4. http://gco.iarc.fr/today/fact-sheets-cancers.

5. PARKIN DM. Cancer incidence in five continents. International Agency for Research on Cancer World Health Organization 1997.

6. Schottenfeld D, Winawer S. Cancers of the large intestine. Cancer epidemiology prevention. 1996;2:813-40.

7. Balakrishnan M, George R, Sharma A, Graham DY. Changing trends in stomach cancer throughout the world. Curr Gastroenterol Rep. 2017;19:36.

8. http://gco.iarc.fr/today/data/factsheets/populations/4-afghanistan-fact-sheets.pdf.

9. González CA, Sala N, Capellá G. Genetic susceptibility and gastric cancer risk. International journal of cancer. 2002;100:249-60.

10. Ahmed N: 23 years of the discovery of Helicobacter pylori: Is the debate over?: Springer; 2005.

11. Ladeiras-Lopes R, Pereira AK, Nogueira A, Pinheiro-Torres T, Pinto I, Santos-Pereira R, Lunet N. Smoking and gastric cancer: systematic review and meta-analysis of cohort studies. Cancer causes control. 2008;19:689-701.

12. Tramacere I, Negri E, Pelucchi C, Bagnardi V, Rota M, Scotti L, Islami F, Corrao G, La Vecchia C, Boffetta P. A meta-analysis on alcohol drinking and gastric cancer risk. Annals of oncology. 2012;23:28-36. 
13. Chang C-J, Tu Y-K, Chen P-C, Yang H-Y. Talc exposure and risk of stomach cancer: Systematic review and meta-analysis of occupational cohort studies. Journal of the Formosan Medical Association 2018.

14. Freedman ND, Chow W-H, Gao Y-T, Shu X-O, Ji B-T, Yang G, Lubin JH, Li H-L, Rothman N, Zheng W. Menstrual and reproductive factors and gastric cancer risk in a large prospective study of women. Gut. 2007;56:1671-7.

15. Yang D, Hendifar A, Lenz C, Togawa K, Lenz F, Lurje G, Pohl A, Winder T, Ning Y, Groshen S. Survival of metastatic gastric cancer: Significance of age, sex and race/ethnicity. Journal of gastrointestinal oncology. 2011;2:77.

16. Gupta S, Tao L, Murphy JD, Camargo MC, Oren E, Valasek MA, Gomez SL, Martinez ME. Race/ethnicity-, socioeconomic status-, and anatomic subsite-specific risks for gastric cancer. Gastroenterology. 2019;156:59-62. e54.

17. Yang P, Zhou Y, Chen B, Wan H-W, Jia G-Q, Bai H-L, Wu X-T. Overweight, obesity and gastric cancer risk: results from a meta-analysis of cohort studies. European journal of cancer. 2009;45:2867-73.

18. De Stefani E, Correa P, Boffetta P, Deneo-Pellegrini H, Ronco AL, Mendilaharsu M. Dietary patterns and risk of gastric cancer: a casecontrol study in Uruguay. Gastric Cancer. 2004;7:211-20.

19. Hansson LE, Nyrén O, Bergström R, Wolk A, Lindgren A, Baron J, Adami HO. Diet and risk of gastric cancer. A population-based casecontrol study in Sweden. International journal of cancer. 1993;55:181-9.

20. Fang X, Wei J, He X, An P, Wang H, Jiang L, Shao D, Liang H, Li Y, Wang F. Landscape of dietary factors associated with risk of gastric cancer: A systematic review and dose-response meta-analysis of prospective cohort studies. Eur J Cancer. 2015;51:2820-32.

21. Shivappa N, Steck SE, Hurley TG, Hussey JR, Hébert JR. Designing and developing a literature-derived, population-based dietary inflammatory index. Public Health Nutr. 2014;17:1689-96.

22. Calder PC, Ahluwalia N, Brouns F, Buetler T, Clement K, Cunningham K, Esposito K, Jönsson LS, Kolb H, Lansink M. Dietary factors and low-grade inflammation in relation to overweight and obesity. Br J Nutr. 2011;106:1-78.

23. Vlassara H, Cai W, Crandall J, Goldberg T, Oberstein R, Dardaine V, Peppa M, Rayfield EJ: Inflammatory mediators are induced by dietary glycotoxins, a major risk factor for diabetic angiopathy. Proceedings of the National Academy of Sciences 2002, 99:15596-15601.

24. Garcia-Arellano A, Ramallal R, Ruiz-Canela M, Salas-Salvadó J, Corella D, Shivappa N, Schröder H, Hébert JR, Ros E, Gómez-Garcia E. Dietary inflammatory index and incidence of cardiovascular disease in the PREDIMED study. Nutrients. 2015;7:4124-38.

25. Lin Y, Ness-Jensen E, Hveem K, Lagergren J, Lu Y. Metabolic syndrome and esophageal and gastric cancer. Cancer Causes Control. 2015;26:1825-34.

26. Wirth MD, Shivappa N, Steck SE, Hurley TG, Hébert JR. The dietary inflammatory index is associated with colorectal cancer in the National Institutes of Health-American Association of Retired Persons Diet and Health Study. Br J Nutr. 2015;113:1819-27.

27. Shivappa N, Zucchetto A, Serraino D, Rossi M, La Vecchia C, Hébert JR. Dietary inflammatory index and risk of esophageal squamous cell cancer in a case-control study from Italy. Cancer Causes Control. 2015;26:1439-47.

28. Shivappa N, Sandin S, Löf M, Hébert JR, Adami H-O, Weiderpass E. Prospective study of dietary inflammatory index and risk of breast cancer in Swedish women. Br J Cancer. 2015;113:1099-103.

29. Shivappa N, Bosetti C, Zucchetto A, Serraino D, La Vecchia C, Hébert JR. Dietary inflammatory index and risk of pancreatic cancer in an Italian case-control study. Br J Nutr. 2015;113:292-8.

30. Shivappa N, Hébert JR, Rosato V, Rossi M, Libra M, Montella M, Serraino D, La Vecchia C. Dietary inflammatory index and risk of bladder cancer in a large Italian case-control study. Urology. 2017;100:84-9.

31. Shivappa N, Hébert JR, Rosato V, Rossi M, Montella M, Serraino D, La Vecchia C. Dietary inflammatory index and ovarian cancer risk in a large Italian case-control study. Cancer Causes Control. 2016;27:897-906.

32. Shivappa N, Bosetti C, Zucchetto A, Montella M, Serraino D, La Vecchia C, Hébert JR. Association between dietary inflammatory index and prostate cancer among Italian men. Br J Nutr. 2015;113:278-83.

33. Shivappa N, Blair CK, Prizment AE, Jacobs DR, Hébert JR. Dietary inflammatory index and risk of renal cancer in the lowa Women's Health Study. Eur J Nutr. 2018;57:1207-13.

34. Lee S, Lee J, Choi IJ, Kim Y-W, Ryu KW, Kim Y-I, Oh J-K, Tran BT, Kim J. Dietary inflammatory index and the risk of gastric cancer in a Korean population. Oncotarget. 2017;8:85452.

35. Vahid F, Shivappa N, Faghfoori Z, Khodabakhshi A, Zayeri F, Hebert JR, Davoodi SH. Validation of a Dietary Inflammatory Index (DII) and association with risk of gastric cancer: A case-control study. Asian Pacific journal of cancer prevention: APJCP. 2018;19:1471.

36. Shivappa N, Hébert JR, Ferraroni M, La Vecchia C, Rossi M. Association between dietary inflammatory index and gastric cancer risk in an Italian case-control study. Nutr Cancer. 2016;68:1262-8.

37. Edwardes MD. Sample size requirements for case-control study designs. BMC Med Res Methodol. 2001;1:11.

Page 7/12 
38. https://metrosouth.health.qld.gov.au/sites/default/files/dietetic-profile-afghan.pdf.

39. Willett W, Stampfer MJ. Total energy intake: implications for epidemiologic analyses. Am J Epidemiol. 1986;124:17-27.

40. Mousavi SM, Rigi S, Shayanfar M, Mohammad-Shirazi M, Sharifi G, Esmaillzadeh A. Refined grains consumption is associated with a greater odds of glioma. Nutr Neurosci 2020:1-9.

41. Agudo A, Cayssials V, Bonet C, Tjønneland A, Overvad K, Boutron-Ruault M-C, Affret A, Fagherazzi G, Katzke V, Schübel R. Inflammatory potential of the diet and risk of gastric cancer in the European Prospective Investigation into Cancer and Nutrition (EPIC) study. Am J Clin Nutr. 2018;107:607-16.

42. Shivappa N, Hébert JR, Steck SE, Hofseth LJ, Shehadah I, Bani-Hani KE, Al-Jaberi T, Al-Nusairr M, Heath D, Tayyem R. Dietary inflammatory index and odds of colorectal cancer in a case-control study from Jordan. Appl Physiol Nutr Metab. 2017;42:744-9.

43. Shivappa N, Hébert JR, Rosato V, Montella M, Serraino D, La Vecchia C. Association between the dietary inflammatory index and breast cancer in a large Italian case-control study. Mol Nutr Food Res. 2017;61:1600500.

44. Shivappa N, Blair CK, Prizment AE, Jacobs DR, Hébert JR. Prospective study of the dietary inflammatory index and risk of breast cancer in postmenopausal women. Mol Nutr Food Res. 2017;61:1600592.

45. Buiatti E, Palli D, Decarli A, Amadori D, Avellini C, Bianchi S, Biserni R, Cipriani F, Cocco P, Giacosa A. A case-control study of gastric cancer and diet in Italy. Int J Cancer. 1989;44:611-6.

46. Ward MH, López-Carrillo L. Dietary factors and the risk of gastric cancer in Mexico City. Am J Epidemiol. 1999;149:925-32.

47. Babaei M, Pourfarzi F, Yazdanbod A, Chiniforush MM, Derakhshan MH, Mousavi SM, Samadi F, Rahimi G. Gastric cancer in Ardabil, Iran-a review and update on cancer registry data. Asian Pac J Cancer Prev. 2010;11:595-9.

48. La Vecchia C, Negri E, Decarli A, D'Avanzo B, Franceschi S. A case-control study of diet and gastric cancer in northern Italy. Int J Cancer. 1987;40:484-9.

49. Kim HJ, Chang WK, Kim MK, Lee SS, Choi BY. Dietary factors and gastric cancer in Korea: A case-control study. Int J Cancer. 2002;97:531-5.

50. Fowler ME, Akinyemiju TF. Meta-analysis of the association between dietary inflammatory index (DII) and cancer outcomes. Int J Cancer. 2017;141:2215-27.

51. Tuyns AJ, Kaaks R, Haelterman M, Riboli E. Diet and gastric cancer. A case-control study in Belgium. Int J Cancer. 1992;51:1-6.

52. Fox JG, Wang TC. Inflammation, atrophy, and gastric cancer. J Clin Investig. 2007;117:60-9.

53. Fox JG, Wang TC. Inflammation, atrophy, and gastric cancer. J Clin Invest. 2007;117:60-9.

54. Ernst $P$. The role of inflammation in the pathogenesis of gastric cancer. Aliment Pharmacol Ther. 1999;13:13-8.

55. La Vecchia C, Ferraroni M, D'Avanzo B, Decarli A, Franceschi S. Selected micronutrient intake and the risk of gastric cancer. Cancer Epidemiology Prevention Biomarkers. 1994;3:393-8.

\section{Tables}

Table 1: General characteristics of study participants 


\begin{tabular}{|c|c|c|c|c|c|c|c|}
\hline & \multirow{3}{*}{$\begin{array}{l}\text { Cases } \\
(\mathrm{n}=90)\end{array}$} & \multirow{3}{*}{$\begin{array}{l}\text { Controls } \\
(\mathrm{n}=180)\end{array}$} & \multirow{3}{*}{$\mathrm{P}^{* *}$} & \multicolumn{4}{|c|}{ Tertiles of DII } \\
\hline & & & & score & & & \\
\hline & & & & 1 & 2 & 3 & $\mathrm{P}^{* *}$ \\
\hline Age (years) & $55 \pm 12$ & $54 \pm 12$ & 0.48 & $53.58 \pm 12$ & $53.68 \pm 12$ & $55.48 \pm 11.37$ & 0.44 \\
\hline Weight (kg) & $63.27 \pm 13.54$ & $74.27 \pm 8.59$ & $<0.001$ & $69.37 \pm 12.49$ & $71 \pm 12.27$ & $71.35 \pm 10.65$ & 0.50 \\
\hline $\operatorname{BMI}\left(\mathrm{kg} / \mathrm{m}^{2}\right)$ & $21.9 \pm 3.72$ & $25.26 \pm 2.4$ & $<0.001$ & $24 \pm 3.39$ & $24.15 \pm 3.42$ & $24.22 \pm 3.02$ & 0.91 \\
\hline $\begin{array}{l}\text { Physical activity (MET- } \\
\text { h/week) }\end{array}$ & $2.2 \pm 0.90$ & $1.6 \pm 0.88$ & $<0.001$ & $1.83 \pm 0.93$ & $1.7 \pm 0.93$ & $1.85 \pm 0.93$ & 0.51 \\
\hline Male (\%) & 73.3 & 72.8 & 0.92 & 71.3 & 72.5 & 74.5 & 0.87 \\
\hline Married (\%) & 80 & 81.7 & 0.74 & 81.3 & 78.8 & 82.7 & 0.78 \\
\hline Residence (rural, \%) & 89 & 42.2 & $<0.001$ & 45 & 55 & 69.1 & 0.003 \\
\hline Ethnicity & & & $<0.001$ & & & & 0.16 \\
\hline Tajik & 42.2 & 52.2 & & 48.8 & 55 & 44.5 & \\
\hline Pashton & 24.4 & 35.6 & & 33.8 & 32.5 & 30 & \\
\hline Hazara & 24.4 & 11.7 & & 17.5 & 11.3 & 18.2 & \\
\hline Uzbek & 7.8 & 0.6 & & 0 & 1.3 & 6.4 & \\
\hline Turkman & 1.1 & 0 & & 0 & 0 & 0.9 & \\
\hline Job (farmer and worker, \%) & 36.7 & 15.6 & $<0.001$ & 22.5 & 23.8 & 21.8 & 0.95 \\
\hline Post graduated education (\%) & 1.1 & 17.8 & $<0.001$ & 16.3 & 13.8 & 8.2 & 0.21 \\
\hline Supplements use (\%) & 1.1 & 5 & 0.11 & 5 & 3.8 & 2.7 & 0.71 \\
\hline Smoking & & & 0.02 & & & & 0.51 \\
\hline day $\begin{array}{l}\text { Less than } 3 \text { cigarettes a } \\
\text { dign }\end{array}$ & 0 & 16.7 & & 6.7 & 7.7 & 4.8 & \\
\hline 3-5 cigarettes a day & 29 & 38.9 & & 20 & 53.8 & 28.6 & \\
\hline 6-9 cigarettes a day & 38.7 & 38.9 & & 40 & 23.1 & 47.6 & \\
\hline$\geq 10$ cigarettes a day & 32.3 & 5.6 & & 33.3 & 15.4 & 19 & \\
\hline Drugs usage (\%) & 13.3 & 3.3 & 0.002 & 6.3 & 6.3 & 7.3 & 0.94 \\
\hline Medicine use (\%) & 36.7 & 26.1 & 0.07 & 30 & 30 & 29.1 & 0.98 \\
\hline History of Diabetes (\%) & 3.3 & 5 & 0.53 & 2.5 & 6.3 & 4.5 & 0.51 \\
\hline History of H.pylori (\%) & 47.8 & 1.1 & $<0.001$ & 16.3 & 12.5 & 20 & 0.38 \\
\hline Family history of cancer (\%) & 31.1 & 5 & $<0.001$ & 12.5 & 10 & 17.3 & 0.33 \\
\hline SES (\%) & & & $<0.001$ & & & & 0.49 \\
\hline Low & 38.9 & 21.1 & & 25 & 26.3 & 29.1 & \\
\hline Middle & 40 & 24.4 & & 23.8 & 33.8 & 30.9 & \\
\hline High & 21.1 & 54.4 & & 51.3 & 40 & 40 & \\
\hline
\end{tabular}

Abbreviations: MET (Metabolic Equivalents), SES (Social Economic Status), DII (Dietary Inflammatory Index), BMI (Body Mass Index) and H.pylori (Helicobacter pylori).

*All values are mean \pm SD unless indicated.

** P values were obtained from independent Student's t test or chi-square test, where appropriate.

Table 2: Dietary habits of study participants 


\begin{tabular}{|c|c|c|c|c|c|c|c|}
\hline & \multirow[b]{2}{*}{$\begin{array}{l}\text { Cases } \\
(\mathrm{n}=90)\end{array}$} & \multirow[b]{2}{*}{$\begin{array}{r}\text { Controls } \\
(n=180)\end{array}$} & \multirow[b]{2}{*}{$\mathrm{P}^{* *}$} & \multicolumn{4}{|c|}{ Tertiles of DII score } \\
\hline & & & & 1 & 2 & 3 & $\mathrm{P} * *$ \\
\hline Drinking tea & & & $<0.001$ & & & & 0.35 \\
\hline Hot & 91.1 & 52 & & 57.7 & 63.6 & 72.2 & \\
\hline Moderate & 7.8 & 45.1 & & 39.7 & 33.8 & 25.9 & \\
\hline Cold & 1.1 & 2.9 & & 2.6 & 2.6 & 1.9 & \\
\hline Kebab food (\%) & 78.9 & 30.6 & $<0.001$ & 35 & 42.5 & 58.2 & 0.005 \\
\hline Fried food consumption (\%) & 91.1 & 52.8 & $<0.001$ & 61.3 & 65 & 69.1 & 0.52 \\
\hline Microwave use (\%) & 5.6 & 6.7 & 0.71 & 3.8 & 7.5 & 7.3 & 0.54 \\
\hline Boiled food usage (\%) & 72.2 & 90 & $<0.001$ & 96.3 & 85 & 74.5 & $<0.001$ \\
\hline Outdoor food usage (\%) & 49.4 & 32.4 & 0.007 & 41.6 & 37.5 & 36.1 & 0.74 \\
\hline Types of oils used (\%) & & & $<0.001$ & & & & 0.01 \\
\hline Solid & 75.6 & 20.6 & & 32.5 & 31.3 & 49.1 & \\
\hline Liquid & 24.4 & 79.4 & & 67.5 & 68.8 & 50.9 & \\
\hline Olive & 0 & 0 & & 0 & 0 & 0 & \\
\hline Salt intake (\%) & & & $<0.001$ & & & & 0.59 \\
\hline Low & 8.9 & 32.2 & & 22.5 & 26.3 & 24.5 & \\
\hline Median & 40 & 63.3 & & 53.8 & 55 & 57.3 & \\
\hline High & 48.9 & 4.4 & & 23.8 & 18.8 & 16.4 & \\
\hline Very high & 2.2 & 0 & & 0 & 0 & 1.8 & \\
\hline Fatty foods (\%) & & & $<0.001$ & & & & 0.96 \\
\hline Low fat & 56.7 & 40.6 & & 45 & 46.3 & 46.4 & \\
\hline Moderate fat & 7.8 & 29.4 & & 25 & 21.3 & 20.9 & \\
\hline High fat & 35.6 & 30 & & 30 & 32.5 & 32.7 & \\
\hline Intra-meal water drinking (\%) & 72.2 & 25 & $<0.001$ & 31.3 & 36.3 & 50.9 & 0.01 \\
\hline Intra-meal drinking of other beverages (\%) & 7.8 & 3.3 & 0.10 & 5 & 6.3 & 3.6 & 0.70 \\
\hline
\end{tabular}

*Abbreviations: DII (Dietary Inflammatory Index)

Table 3: Food intakes of study participants

\begin{tabular}{|c|c|c|c|c|c|c|c|}
\hline & \multirow[b]{2}{*}{$\begin{array}{l}\text { Cases } \\
(\mathrm{n}=90)\end{array}$} & \multirow[b]{2}{*}{$\begin{array}{l}\text { Controls } \\
(\mathrm{n}=180)\end{array}$} & \multirow[b]{2}{*}{$\mathrm{P} *$} & \multicolumn{3}{|c|}{ Tertiles of DII score } & \multirow[b]{2}{*}{$\mathrm{P} * *$} \\
\hline & & & & 1 & 2 & 3 & \\
\hline & Mean \pm SE & Mean \pm SE & & Mean \pm SE & Mean \pm SE & Mean \pm SE & \\
\hline \multicolumn{8}{|l|}{ Food groups } \\
\hline Refined grains $(\mathrm{g} / \mathrm{d})$ & $381.47 \pm 26.66$ & $378.02 \pm 18.84$ & 0.91 & $387.93 \pm 28.28$ & $355.25 \pm 28.27$ & $390.19 \pm 24.14$ & 0.6 \\
\hline Whole-grains (g/d & $307.36 \pm 22.29$ & $211.81 \pm 15.76$ & 0.001 & $167.94 \pm 22.99$ & $209.87 \pm 22.99$ & $323.31 \pm 19.63$ & $<0.001$ \\
\hline $\begin{array}{l}\text { Fish and poultry } \\
(\mathrm{g} / \mathrm{d})\end{array}$ & $46.34 \pm 2.96$ & $22.47 \pm 2.09$ & $<0.001$ & $30.62 \pm 3.38$ & $33.18 \pm 3.38$ & $28.29 \pm 2.89$ & 0.54 \\
\hline Fruits $(\mathrm{g} / \mathrm{d})$ & $40.35 \pm 5.48$ & $73.47 \pm 3.87$ & $<0.001$ & $76.23 \pm 5.92$ & $69.04 \pm 5.92$ & $47.58 \pm 5.05$ & 0.001 \\
\hline Vegetables (g/d) & $363.37 \pm 19.51$ & $388.01 \pm 13.79$ & 0.304 & $503.66 \pm 18.51$ & $360.12 \pm 18.51$ & $304.02 \pm 15.8$ & $<0.001$ \\
\hline $\begin{array}{l}\text { Dairy products } \\
\text { (g/d) }\end{array}$ & $70.85 \pm 10.05$ & $166.6 \pm 7.1$ & $<0.001$ & $160.4 \pm 11.62$ & $139.54 \pm 11.61$ & $112.45 \pm 9.92$ & 0.007 \\
\hline $\begin{array}{l}\text { Legumes and nuts } \\
(\mathrm{g} / \mathrm{d})\end{array}$ & $94.74 \pm 6.51$ & $120.56 \pm 4.6$ & 0.001 & $135.48 \pm 6.68$ & $120.21 \pm 6.68$ & $88.83 \pm 5.71$ & $<0.001$ \\
\hline Green/black tea & $751.08 \pm 48.64$ & $473.42 \pm 34.38$ & $<0.001$ & $586.52 \pm 53.7$ & $532.4 \pm 53.69$ & $575.46 \pm 45.85$ & 0.74 \\
\hline $\begin{array}{l}\text { Red and processed } \\
\text { meat }(\mathrm{g} / \mathrm{d})\end{array}$ & $40.13 \pm 2.38$ & $17.72 \pm 1.68$ & $<0.001$ & $22.9 \pm 2.79$ & $26.76 \pm 2.79$ & $25.72 \pm 2.38$ & 0.59 \\
\hline Pepper $(\mathrm{g} / \mathrm{d})$ & $16.96 \pm 1.11$ & $13.46 \pm 0.79$ & 0.01 & $20.75 \pm 1.1$ & $14.34 \pm 1.1$ & $10.37 \pm 0.94$ & $<0.001$ \\
\hline
\end{tabular}

*Abbreviations: DII (Dietary Inflammatory Index).

Table 4: Nutrients intakes of study participants 


\begin{tabular}{|c|c|c|c|c|c|c|c|}
\hline & & & & & ertiles of DII score & & \\
\hline & $\begin{array}{c}\text { Cases } \\
(\mathrm{n}=90)\end{array}$ & $\begin{array}{l}\text { Controls } \\
(\mathrm{n}=180)\end{array}$ & $\mathrm{P}^{*}$ & 1 & 2 & 3 & $\mathrm{P}^{* *}$ \\
\hline & Mean \pm SE & Mean \pm SE & & Mean \pm SE & Mean \pm SE & Mean \pm SE & \\
\hline rgy (kcal/d) & $3190.51 \pm 109.45$ & $2836.15 \pm 77.37$ & 0.009 & $2873.88 \pm 117.23$ & $2858.15 \pm 117.07$ & $3082.64 \pm 100$ & 0.25 \\
\hline rients & & & & & & & \\
\hline $\begin{array}{l}\text { arbohydrates } \\
\mathrm{g} / \mathrm{d} \text { ) }\end{array}$ & $461.41 \pm 5.15$ & $458.61 \pm 3.64$ & 0.658 & $440.68 \pm 4.92$ & $443.09 \pm 4.92$ & $485.23 \pm 4.2$ & $<0.001$ \\
\hline 'roteins (g/d) & $91.32 \pm 0.73$ & $87.56 \pm 0.52$ & $<0.001$ & $88.32 \pm 0.8$ & $89.7 \pm 0.8$ & $88.54 \pm 0.68$ & 0.42 \\
\hline $\begin{array}{l}\text { otal fats } \\
\mathrm{g} / \mathrm{d})\end{array}$ & $86.42 \pm 2.27$ & $90.24 \pm 1.60$ & 0.171 & $98.64 \pm 2.13$ & $96.17 \pm 2.13$ & $76.69 \pm 1.82$ & $<0.001$ \\
\hline $\begin{array}{l}\text { holesterol } \\
\mathrm{mg} / \mathrm{d})\end{array}$ & $162.02 \pm 10.26$ & $167.23 \pm 7.25$ & 0.679 & $185.57 \pm 10.73$ & $173.18 \pm 10.73$ & $145.3 \pm 9.16$ & 0.01 \\
\hline FA $(\mathrm{g} / \mathrm{d})$ & $18.79 \pm 0.64$ & $19.65 \pm 0.45$ & 0.28 & $20.67 \pm 0.65$ & $21.41 \pm 0.65$ & $16.93 \pm 0.55$ & $<0.001$ \\
\hline IUFA (g/d) & $16.97 \pm 0.50$ & $15.84 \pm 0.35$ & 0.06 & $17.58 \pm 0.5$ & $17.77 \pm 0.5$ & $14.09 \pm 0.42$ & $<0.001$ \\
\hline 'UFA (g/d) & $15.10 \pm 0.67$ & $26.73 \pm 0.47$ & 0.04 & $29.69 \pm 0.62$ & $27.69 \pm 0.62$ & $22.54 \pm 0.53$ & $<0.001$ \\
\hline $\mathrm{e}(\mathrm{mg} / \mathrm{d})$ & $21.26 \pm 0.447$ & $21.21 \pm 0.316$ & 0.925 & $22.1 \pm 0.46$ & $21.54 \pm 0.46$ & $20.36 \pm 0.39$ & 0.01 \\
\hline $\lg (\mathrm{mg} / \mathrm{d})$ & $200.97 \pm 5.25$ & $227.34 \pm 3.71$ & $<0.001$ & $266.72 \pm 3.81$ & $229.13 \pm 3.81$ & $175.81 \pm 3.25$ & $<0.001$ \\
\hline $\mathrm{n}(\mathrm{mg} / \mathrm{d})$ & $5.99 \pm 0.175$ & $6.34 \pm 0.124$ & 0.104 & $7.18 \pm 0.15$ & $6.69 \pm 0.15$ & $5.2 \pm 0.13$ & $<0.001$ \\
\hline e $(\mathrm{mg} / \mathrm{d})$ & $0.019 \pm 0.002$ & $0.028 \pm 0.001$ & $<0.001$ & $0.03 \pm 0.002$ & $0.02 \pm 0.002$ & $0.01 \pm 0.002$ & $<0.001$ \\
\hline $\begin{array}{l}\text { hiamine } \\
\mathrm{mg} / \mathrm{d})\end{array}$ & $2.38 \pm 0.028$ & $2.31 \pm 0.02$ & 0.032 & $2.25 \pm 0.02$ & $2.27 \pm 0.02$ & $2.44 \pm 0.02$ & $<0.001$ \\
\hline $\begin{array}{l}\text { iboflavin } \\
\mathrm{mg} / \mathrm{d})\end{array}$ & $0.98 \pm 0.04$ & $1.29 \pm 0.028$ & $<0.001$ & $1.39 \pm 0.04$ & $1.3 \pm 0.04$ & $0.95 \pm 0.03$ & $<0.001$ \\
\hline Jiacin $(\mathrm{mg} / \mathrm{d})$ & $29.81 \pm 0.29$ & $25.87 \pm 0.207$ & $<0.001$ & $26.02 \pm 0.36$ & $27.15 \pm 0.36$ & $28.06 \pm 0.31$ & $<0.001$ \\
\hline $\begin{array}{l}\text { Titamin B6 } \\
\text { mg/d) }\end{array}$ & $1.21 \pm 0.035$ & $1.31 \pm 0.02$ & 0.016 & $1.57 \pm 0.02$ & $1.33 \pm 0.02$ & $1.02 \pm 0.02$ & $<0.001$ \\
\hline $\begin{array}{l}\text {-carotene } \\
\mathrm{mcg} / \mathrm{d})\end{array}$ & $1711.32 \pm 99.22$ & $1612.49 \pm 70.14$ & 0.417 & $2272.21 \pm 87.93$ & $1832.58 \pm 87.9$ & $1053.49 \pm 75.06$ & $<0.001$ \\
\hline $\begin{array}{l}\text { Titamin A } \\
\mathrm{RE} / \mathrm{d})\end{array}$ & $1511.24 \pm 89.47$ & $1552.3 \pm 63.24$ & 0.71 & $2104 \pm 78.36$ & $1730.79 \pm 78.34$ & $987.83 \pm 66.89$ & $<0.001$ \\
\hline $\begin{array}{l}{ }_{\text {Titamin }} \mathrm{C} \\
\mathrm{mg} / \mathrm{d})\end{array}$ & $121.32 \pm 4.61$ & $131.61 \pm 3.26$ & 0.071 & $168.09 \pm 3.73$ & $128.39 \pm 3.73$ & $98.99 \pm 3.18$ & $<0.001$ \\
\hline $\begin{array}{l}{ }_{\text {Titamin }} \mathrm{E} \\
\mathrm{mg} / \mathrm{d})\end{array}$ & $1.82 \pm 0.085$ & $2.76 \pm 0.06$ & $<0.001$ & $3.23 \pm 0.07$ & $2.52 \pm 0.07$ & $1.82 \pm 0.06$ & $<0.001$ \\
\hline $\begin{array}{l}\text { itamin D } \\
\mathrm{mcg} / \mathrm{d})\end{array}$ & $0.461 \pm 0.074$ & $1.072 \pm 0.05$ & $<0.001$ & $1.04 \pm 0.08$ & $0.93 \pm 0.08$ & $0.65 \pm 0.07$ & 0.001 \\
\hline $\begin{array}{l}\text { Iitamin B12 } \\
\mathrm{mcg} / \mathrm{d})\end{array}$ & $1.53 \pm 0.073$ & $1.75 \pm 0.052$ & 0.016 & $1.84 \pm 0.07$ & $1.8 \pm 0.07$ & $1.47 \pm 0.06$ & $<0.001$ \\
\hline $\begin{array}{l}\text { 'olate } \\
\mathrm{mcg} / \mathrm{d})\end{array}$ & $249.15 \pm 7.42$ & $286.83 \pm 5.24$ & $<0.001$ & $334.78 \pm 6.05$ & $288.21 \pm 6.05$ & $220.12 \pm 5.16$ & $<0.001$ \\
\hline $\begin{array}{l}\text { )ietary fiber } \\
\text { g/d) }\end{array}$ & $17.64 \pm 0.406$ & $20.53 \pm 0.287$ & $<0.001$ & $23.1 \pm 0.33$ & $20.15 \pm 0.33$ & $16.57 \pm 28$ & $<0.001$ \\
\hline
\end{tabular}

*Abbreviations: DII (Dietary Inflammatory Index), SFA (Saturated Fatty Acid), MUFA (Monounsaturated Fatty Acid), PUFA (Polyunsaturated Fatty Acid), Fe (Iron), Mg (Magnesium), Zn (Zinc), Se (Selenium).

**All values were adjusted for age and sex, except for dietary energy intake, which was only adjusted for age and sex using ANCOVA.

Table 5: Odds ratios (ORs) and 95\% confidence intervals (95\% CIs) of gastric cancer according to tertiles of dietary inflammatory index

\begin{tabular}{|c|c|c|c|c|}
\hline & \multicolumn{3}{|c|}{ Tertiles of DII score } & \multirow[t]{2}{*}{ P-trend* } \\
\hline & 1 & 2 & 3 & \\
\hline \multirow[b]{2}{*}{ Crude } & OR & OR $(95 \%$ CI) & OR (95\% CI) & \\
\hline & 1.00 & $1(0.48-2.04)$ & 2.50 (1.33-4.69) & 0.002 \\
\hline Model 1 & 1.00 & $1(0.48-2.04)$ & $2.47(1.31-4.66)$ & 0.002 \\
\hline Model 2 & 1.00 & $1.40(0.40-4.87)$ & $3.59(1.16-11.02)$ & 0.01 \\
\hline Model 3 & 1.00 & 1. $59(0.42-6.06)$ & $3.75(1.14-12.30)$ & 0.01 \\
\hline
\end{tabular}

*Binary logistic regression was used to obtain OR and 95\% CI. The overall trend of OR across increasing tertiles was examined by considering the median score in each category as a continuous variable. 
Model 1: adjusted for age (continuous), gender (male/female).

Model 2: further adjustments were made for age (continuous), gender (male/female), physical activity (categorical), and family history of cancer (yes/no), SES (low, middle and high), Kebab food (categorical), smoking usage (categorical), drugs usage (yes/no) and H. pylori infection (yes/no).

Model 3: additionally, adjusted for BMI (categorical)+Model 2. 